\title{
"Grandes olhos negros": o ícone literário da princesa fenícia 'Îzebel na corte israelita do século IX A.E.C. nos contextos das linguagens culturais levantinas
}

\author{
João Batista Ribeiro Santos*
}

\section{Resumo}

Este artigo tem por objetivo analisar - no contexto dos usos de testemunhos artefactuais e literários, resultados da difusão de saberes políticos e cúlticos - a iconização literária da princesa fenícia 'Îzebel, compilada na historiografia israelita. A agente cultural é a princesa fenícia e o nosso artefato são as camadas literárias de 2Reis 9, com datação entre os séculos VIII e IV A.E.C. Tanto a agente quanto o artefato são ambientados, inicialmente, nos contextos dos conflitos políticos no sul do Levante na segunda metade do século IX A.E.C. e, posteriormente, nos conflitos culturais do judaísmo antigo - um sinal indiciário da mudança de critério no julgamento de 'Îzebel. O julgamento, motivado pelo assassinato de um camponês, findou-se com uma condenação ancorada na acusação de promover a patrono real o deus tutelar de Tiro (Șūr) Melqart. A nossa hipótese é que as interações culturais provocaram a reação de camponeses, cuja liderança apoiou a tomada de poder por parte do militar de origem rural Jehu. Contextualizaremos a narração historiográfica que compôs a imagem de 'Îzebel com as culturas iconográficas levantinas.

Palavras-chave: Memória cultural. Bíblia hebraica. Linguagem cultural. Jezebel. Levante.

\section{"Great black eyes": the literary icon of the Phoenician princess 'Îzebel at the 9th century B.C.E. Israeli court in the contexts of the Levantine cultural languages}

\begin{abstract}
This article aims to analyze - in the context of the uses of artifactual and literary testimonies, results of the diffusion of political and cultic knowledge - the literary iconization of the Phoenician 'Izzebel princess, compiled in the Israeli historiography.

* Professor da Faculdade de Teologia da Universidade Metodista de São Paulo (FATEO/ UMESP). Mestre em História Política (História Antiga) pela Universidade do Estado do Rio de Janeiro (UERJ), mestre e doutor em Ciências da Religião (Literatura e religião no mundo bíblico) pela UMESP, e pós-doutorando em História (História Antiga) na Universidade Estadual Paulista (FCL/UNESP-Assis). E-mail: joao.ribeiro@metodista.br.
\end{abstract}


The cultural agent is the Phoenician princess and our artifact are the literary layers of 2 Kings 9, dated between the 8th and 4th centuries B.C.E. Both the agent and the artifact are initially set in the contexts of the political conflicts in southern Levant in the second half of the ninth century. B.C.E. and thereafter the cultural conflicts of ancient Judaism - an indicia signal of the change of criteria in the judgment in the judgment of 'Izzebel. The judgment, motivated by the murder of a peasant, ended with a condemnation based on the accusation of promoting the royal patron the tutelary god of Tyre $(S \bar{u} r)$ Melqart. Our hypothesis is that cultural interactions provoked the reaction of peasants, whose leadership supported the seizure of power by rural military Jehu. We will contextualize the historiographical narration that composed the image of 'Îzebel with Levantine iconographic cultures.

Keywords: Cultural memory. Hebrew Bible. Cultural language. Jezebel. Levant.

\section{"Grandes ojos negros": el ícono literario de la princesa fenicia 'Îzebel en la corte israelí del Siglo IX A.E.C. en los contextos de los lenguajes culturales levantinos}

\section{Resumen}

El objetivo de este artículo es analizar - en el contexto de los usos de testimonios artifactuales y literarios, los resultados de la difusión del conocimiento político y cultural - la iconización literaria de la princesa fenicia de 'Îzebel, recopilada en la historiografía israelí. El agente cultural es la princesa fenicia y nuestro artefacto son los estratos literarios de 2 Reyes 9, datados entre los siglos VIII y IV A.E.C. Tanto el agente como el artefacto están ubicados inicialmente en los contextos de conflictos políticos en el sur del Levante en la segunda mitad del siglo IX A.E.C. y, más tarde, en los conflictos culturales del antiguo judaísmo - una señal indicador del cambio de juicio en el juicio de 'Îzebel. El juicio, motivado por el asesinato de un campesino, terminó con una condena basada en la acusación de promover al patrón real el dios tutelar de Tiro $(S \hat{u} \bar{r})$ Melqart. Nuestra hipótesis es que las interacciones culturales provocaron la reacción de los campesinos, cuyo liderazgo apoyó la toma del poder por parte de lo militar rural Jehu. Contextualizaremos la narrativa historiográfica que compuso la imagen de 'Îzebel con las culturas iconográficas levantinas.

Palabras clave: Memoria cultural. Biblia hebrea. Lenguaje cultural. Jezebel. Levante.

\section{Postulado introdutório à literatura}

Não sendo as inscrições monumentais "uma explicação etnográfica", como lembra Katherine Southwood (2016, p. 56), a propósito da Bíblia hebraica, resta-nos pesquisá-las não como registros tradicionais de "um informante nativo", mas como fontes que devem ser "registradas, organizadas, comparadas, agrupadas e interpretadas". Assim como todas as compilações de epopeias, fábulas e lendas, pontos de vista ou visões de acontecimento e historiografias palaciais de pretensões nacionais, a Bíblia hebraica também tem em suas "realidades" vieses ideológicos, míticos e ritualísticos. 
$\mathrm{Na}$ Bíblia hebraica, especificamente no livro dos Reis, na última camada redacional da assim chamada história deuteronomística, os escribas e editores utilizaram fontes da Idade do Ferro II (fontes pré-deuteronomísticas), mas as linguagens nos mostram que há muitas categorias com objetivações e cenários do período Persa Aquemênida. Os grandes reis de Israel Norte (Yiśrā'è $)$ e de Judah (Yəhûdāh) estão presentes, seja em monumentos documentais, seja em inscrições, em anais neoassírios, neobabilônios e semitas do Levante. É necessário, no entanto, que distingamos a escrita hebraica entre as linguagens dos povos levantinos:

Evidência linguística, geralmente negligenciada por teólogos, historiadores e arqueólogos, apontam para uma forte continuidade de povos e culturas desde a Idade do Bronze Tardio, visto que o material do segundo milênio já exibe várias características fonológicas e morfológicas das variedades canaanitas posteriores. Este fato, no entanto, não descarta a possibilidade de alguns recém-chegados serem rapidamente integrados.

É contra tal plano de fundo que surgiu o hebraico. O corpus da Bíblia hebraica foi unificado ao longo de muitos processos de redação, e a tradição de pronunciação posterior foi discutivelmente afetada pelo aramaico. Mesmo assim, vestígios de uma diversidade interna, outrora considerável, nos aspectos históricos, geográficos e sociais sobrevivem. Certas composições poéticas são amplamente consideradas até o século XI A.E.C. Seu caráter arcaico ou arcaizante resulta das convenções de uma tradição poética oral anterior também refletida na epopeia ugarítica (GZELLA, 2014, p. 29; tradução do autor). ${ }^{1}$

Com relação à historiografia da emergência real de Jehu $(Y \bar{e} h \hat{u})$, as camadas literárias hebraicas de 2Reis 9-10, podemos situá-la no contexto de

\footnotetext{
1 "Linguistic evidence, generally neglected by theologians, historians, and archaeologists, points to a strong continuity of peoples and cultures since the Late Bronze Age, as secondmillennium material already exhibits several phonological and morphological features of later Canaanite varieties. This fact, however, does not rule out the possibility of some newcomers being quickly integrated.

It is against such a background that Hebrew emerged. The corpus of the Hebrew Bible has been unified over the course of many redactional processes, and the garb of later pronunciation traditions was arguably affected by Aramaic. Even so, traces of a once considerable internal diversity in historical, geographical, and social respects survive. Certain poetic compositions are widely considered to date from around the 11 th century BCE. Their archaic, or archaizing, character results from the conventions of an earlier oral poetic tradition also reflected in Ugaritic epic" (GZELLA, 2014, p. 29).
} 
uma sequência de ataques satíricos, à maneira de paródia ugarítica, ${ }^{2}$, que tem início na narração da "guerra de divindades" no monte Karmel (SANTOS, 2018), é revisada como farsa ${ }^{3}$ e retomada perspectivamente sobre o cerco de Samaria (Sämirina; hebraico: Šōmərôn). ${ }^{4}$ Nesse caso, a ironia subverte a norma historiográfica, mas não justifica adequadamente as ações antissamaritanas. Há o aspecto propagandístico e mimesis, mas também há História porque a linguagem é eminentemente um fato social. ${ }^{5}$

\section{A Epigrafia ${ }^{6}$ de 2 Reis $9^{7}$}

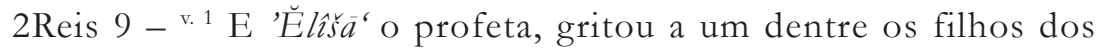

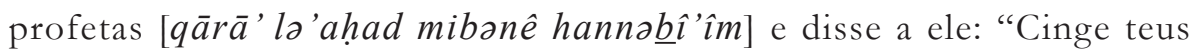
lombos ${ }^{8}$ e pega este frasco de óleo na tua mão e vai (a) Rāmōt Gila ‘àd;

v. 2 e irás para lá e verás lá Yēhù', filho de Yahôšāpāt, filho de Niməš̂̂, e entrarás e lhe farás levantar do meio dos irmãos dele, e farás ele ir quarto escuro em quarto escuro.

${ }^{\text {v. }}{ }^{3}$ E pegarás o frasco do óleo, e derramarás sobre a cabeça dele, e dirás: 'Assim disse Yhwh: ungi-te para rei sobre Yiśrà'èe. E abrirás a porta, e escaparás e não te demorarás".

${ }^{v}{ }^{4} \mathrm{E}$ foi o jovem, o jovem anunciador [hanna'ar hannābî̀'] (para) Rāmōt Gilo 'ād.

2 Michael S. Moore (2003, p. 101, 106-107) traça um paralelo entre a "purificação de Jehu" (purifying agent) em 2Reis 9.14-10.36 e a "purificação de Anat" (Anat's purge), em KTU (Die keilalphabetischen Texte aus Ugarit, Münster) 1.3 i-iii.

3 Cf. 2Reis 6.8-23 (ELLIGER; RUDOLPH, 1997).

4 Em 2Reis 6.24-7.20 (ELLIGER; RUDOLPH, 1997) há uma paródia do debate entre Kothar-wa-Hasis e Ba'al, o motivo da intriga em 2Reis 7.2.

5 Entendemos que a conceituação de Antoine Meillet (2016, p. 57) é proveitosa: o sentido das expressões está sujeito a variações em decorrência das circunstâncias que o determinam, mas também em função da grandeza social; as expressões são marcadoras de autonomia da grandeza social.

6 Na tradução, a "camada pré-deuteronomística" inicia sempre na margem da página, $c$. séculos IX-VIII a.C.; a "camada deuteronomística", c. século VII-VI a.C., recebeu um recuo distintivo e as "adições tardias" receberam dois recuos, c. século V a.C. Foram destacados em negrito os versículos que dizem respeito diretamente a Jezebel.

7 As citações de textos da Bíblia hebraica são da Biblia Hebraica Sttutgartensia (ELLIGER; RUDOLPH (Hrsg.), 1997), assim como as transliterações e traduções realizadas pelo autor. Em relação à Septuaginta, cf. as citações em: RAHLFS; HANHART (Hrsg.), 2006.

8 "Prepare-se você mesmo (esteja) pronto." 
"Grandes olhos negros": o icone literário da princesa fenícia 'Îzebel na corte

israelita do século IX A.E.C. nos contextos das linguagens culturais levantinas

${ }^{\text {v. } 5}$ E entrou, e eis que os chefes da guarnição que se assentavam; e

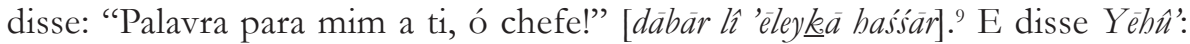
"A quem dentre todos nós?". E disse: "A ti, ó chefe!".

v. 6a E se levantou e foi para a casa, e derramou o óleo sobre a cabeça dele, e disse a ele: "Assim disse Yhwh,

v. 6b Deus de Yiśrà'èl ['ělōhèy Yiśrà'ēn: 'ungi-te para rei [lamelek] ao povo de Yhwh ['el-'am Yhwh], ao lado de Yiśrà'e-p'".

v. 7a E ferirás a bêt 'Ah' 'àb, teus senhores;

v. 7b e vingarei sangues dos meus adoradores [damê 'ăbāday], os profetas [hannab $\underline{\hat{\imath}} \hat{\imath} \hat{\imath} m]$, e sangues de todos os adoradores ${ }^{10}$ de Yhwh $[k \bar{o} l$ 'abadê Yhwh], da mão de 'T́zebel.

${ }^{v}{ }^{8} \mathrm{E}$ perecerá toda a bêt 'Ah'āb [kōl-bêt 'Ah'āb]; e eliminarei lo'Ah'āb o que urina contra parede [mašatîn baqîr], e o que (está) detido, e o que (foi) deixado em Yiśrà'èl.

v. 9 E darei a bêt 'Aḥ'āb, como (a) bêt Yārābə 'ām, filho de Nabāt; e como (a) bêt Ba' 'š̌̄a', filho de 'Ăhiyyāh .

v. 10a E a 'Ízebel comerão os cães na porção de terra de Yizra 'e'l [baḥeleq Yizra 'e'l] e inexistirá coveiro [wa'ên qōbēr].

v. $10 \mathrm{~b}$ E abriu a porta e escapou.

v. 11 E Yèhû' saiu em direção aos escravos dos senhores deles, e disse a ele [wayyōmer]:11 "Há šālôm? Por que veio este que enlouqueceu $[b \bar{a}$ 'haməšuggā' hazzeh] a ti?". E respondeu [=Yēhu'] a eles: "Vós conheceis o homem e a fala dele". ${ }^{12}$

v. 12 E disseram: "Mentira, relata, agora, para nós". Então, disse mesmo assim e isto disse a mim, dizendo: "Assim disse Yhwh: 'Ungi-te para rei para ['el-] Yiśrà'ép'". ${ }^{13}$

9 Ressaltemos a característica sintática do artigo em haśśār, "o substantivo comum está em aposição apenas ao pronome de segunda pessoa”, nesse caso, implícito (WALTKE; O’CONNOR, 2006, p. 247); em adição, a nossa tradução do versículo diferencia da tradução apresentada pelos autores citados.

10 Optamos por traduzir 'ăbāday como "meus adoradores", para situar a expressão no campo religioso.

11 Aqui o verbo hebraico está no singular (wayyōmer); como se refere "aos escravos", pode-se entender no plural: "e disseram a ele”. Quanto à expressão hebraica gerem hamma'ălôt não era entendida como a transliteração registrada na Septuaginta, garem.

12 Ler wy'mrw com muitas versões.

13 Kāzō't wakāzō't é uma taquigrafia indicativa de que uma expressão repetida precedentemente está sendo evitada. 
v. 13 E se apressaram e pegaram cada um ['̂̀'s] roupa dele, e colocaram debaixo dele, em direção à ossatura dos degraus ['el-gerèm hamma'ălôt]; ${ }^{14} \mathrm{e}$ tocaram no chifre e disseram: "Reina Yéhn".

v. 14 E conspirou [wayyitaqaššèr] Yēhû', filho de Yahôšāpāt, filho de Niməšî, contra Yôrām; e Yôrām era guardião em Rāmōt Gilə 'àd, ele e todo Yiśrà'ēl, defronte [mippənēy] a Hăaz̄'èl, rei de 'Ărām.

v. ${ }^{15} \mathrm{E}$ fixou residência [wayyāšā $\underline{b}$ ] Yahôrām, o rei, para se curar em Yizra ' $e$ ' $l$ das feridas que o feriram os aramitas no guerrear dele contra $H \breve{a} z \bar{a}$ 'ēl, rei de 'Áràm. E disse Yēhû': "Se existe gosto ['im-yēš nap̌̌zkem], ${ }^{15}$ que não saia sobrevivente da cidade para ir para relatar ${ }^{16}$ em Yizra 'e 'l'.

v. ${ }^{16}$ Então cavalgou Yèhù', e foi (para) Yizra 'e’l porque Yôrām o que se deitava ali [šāmmāh]; e 'Ăhazəyāh, rei de Yahûdāh, desceu para ver a Yôrām. ${ }^{v}{ }^{17} \mathrm{E}$ o que vigiava o que ficava ${ }^{17}$ sobre a torre em Yizrə 'e'l, e viu a multidão de Yēhû' no ir dele, e disse: "multidão de eu ['ănî] o que vê". Então, disse Yahôrām: "Pega o ginete e envia para lhes falar [liqrätām] e dizer: 'Há šălôm?"'

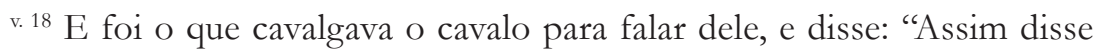

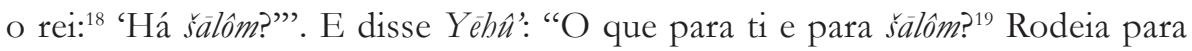
atrás de mim”. E relatou o que vigiava, dizendo: "Chegou o mensageiro até eles, ${ }^{20}$ mas não retornou”.

v. ${ }^{19}$ E enviou o que cavalgava cavalo segundo, e foi a eles, e disse: "Assim disse o rei: 'Šălôm?". ${ }^{21} \mathrm{E}$ disse Yēhû': "O que para ti e para šălôm? Rodeia para atrás de mim".

${ }^{v}{ }^{20}$ E relatou o que vigiava, dizendo: "Chegou até eles, ${ }^{22}$ mas não retornou; e a maneira de conduzir (é) como a maneira de conduzir de Yèhû', filho de Niməšî̀, pois com loucura conduz [bašiggā'ôn yinhāg]'.

Pode-se ler de forma sincopada "sobre os degraus".

15 'im yēš ('et) napšzkem ocorre uma vez no livro do Gênesis 23.8, e em muitos manuscritos a partícula 'et é acrescentada, diferente da citação deuteronomística no livro do profeta Jeremias 15.1 .

16 Ketib (o que está escrito) lgyd; Qerê (o que ler) lhgyd.

17 Ler 'ömèd: "posto", "lugar".

18 A mensagem real é introduzida com a fórmula usual das mensagens divinas, repetida no versículo 19.

19 Destacar-se-á o l; "o objeto geralmente é pessoal", e a expressão foi traduzida por Bruce K. Waltke e Michael P. O’Connor (2006, p. 324-325) por: “Que tens tu com a paz?”.

20 'ad hèm é forma anômala para 'ădêhem.

21 Em várias versões consta hšlwm.

22 ad 'ălêhem é uma leitura duplicada; a leitura simples seria 'ălêhem ou 'ădêhem. 
${ }^{v}{ }^{21}$ E disse Yəhôrām: "Aparelha!". E aparelhou (o) carro de guerra dele. E saiu Yəhôrām, rei de Yiśräèl, e 'Ăhazəyāhû, rei de Yəhûdāh, cada um [’̂̀] no seu carro de guerra; e saíram para o encontro de Yêĥ̀' [wayyēșa 'û liqara 't Yēbû̀], e encontraram na porção de terra de Nābôt, o yizra 'ée'lî.

${ }^{v}{ }^{22} \mathrm{E}$ aconteceu, conforme avistar Yəhôrām a Yēhû' [wayəhî kira'ôt Yahôrām 'et- Yēhû̀'], e disse: “Há šălôm Yēhûu'?”. E respondeu [=Yēhû']: "Que (é) o šălôm [māh haššālôm], enquanto ${ }^{23}$ prostituições ['ad-zanûn] de 'Îzebel, tua mãe, e feitiçarias dela [ûk

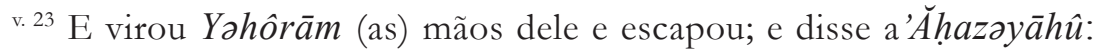
“Traição [mirəmāh], 'Ạhazəyāh!".

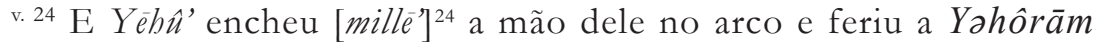
entre (os) braços dele, e saiu a lança [ḥeṣ̂îl] desde o coração dele; e tombou no carro de guerra dele. ${ }^{25}$

v. ${ }^{25} \mathrm{E}$ disse a Bidqar, escudeiro dele:26 "Carrega, lança-o na porção de terra do campo de Nābôt, o yizra 'ée'lî, porque recorda, ${ }^{27}$ eu e tu, os que cavalgam parelhas atrás de 'Aḥ'āb, pai dele, e Yhwh pronunciou sobre ele esta carga".

${ }^{\text {v. } 26}$ Se não os sangues de Nābôt e os sangues dos filhos dele, vi, ontem à noite ['emes'], oráculo de Yhwh, e retribuiria para ti nesta parcela de terra, oráculo de Yhwh, e agora, carrega, lança-o na parcela de terra, conforme a palavra de Yhwh.

v. 27aba E 'Ăhazayāh, rei de Yəhûdāh, viu e escapou caminho da casa do jardim [bêt haggān]; e perseguiu atrás dele Yèbû̀, e disse também a ele: "Feri-o [hakubût ${ }^{28}$ sobre a carruagem, na subida de Gûr, que (está) junto $\alpha$ Yibla 'àm". ${ }^{29}$

23 O sentido básico da preposição 'ad é alativo (movimento em direção a) - terminativo (movimento até); 'ad relacionado ao substantivo tem sentido de "futuro". Nesse versículo, seguimos Waltke e O’Connor (2006, p. 215), traduzindo por “enquanto".

24 O verbo millè' pode ter similaridade com a expressão acadiana qaštu malîtu, "um arco completo", que reconstruiria o hebraísmo millē' haqqě̌et bayad (COGAN; TADMOR, 1988, p. 110). A expressão "encher a mão" é tecnicismo para "investir" contra alguém, $m l$ ' $y d w$ no "Rolo do Templo" (11Q19.15.15-16) (MOORE, 2003, p. 110, n. 72).

25 No texto massorético, barikbô, "em seu carro". A Septuaginta pressupõe o hebraico babirkāyw, "sobre seus joelhos".

26 Ler Qerê, šălišô, "seu encarregado", em lugar do Ketiv, šălišōh, que também significa "seu encarregado".

27 Há versões em que o massorético zəkōr é lido como zōkēre "eu rememoro, lembro".

28 Texto massorético hkhw, enquanto na Septuaginta inscreve-se wykhw, um verbo necessário para descrever o cumprimento do comando.

29 Ybla 'àm tem como nome antigo Bal'ameh, wādī na proximidade do vale de Yizro 'e'l e Khirbet Bel'ameh, $2 \mathrm{~km}$ ao sul de Jenin. 
v. 27bß E escapou (para) Magiddô, e morreu ali.

${ }^{\text {v. }}{ }^{28} \mathrm{E}$ transportaram a ele os escravos dele para Yarû́̌̌ălāmāh; e sepultaram a ele no sepulcro dele, com os pais dele, na cidade de Däwid.

${ }^{v}{ }^{29} \mathrm{E}$ em ano de onze ano [ûbiššnat 'ahat 'eśrēh šānāh] para Yôrām [laYôrām], filho de 'Aḥ'āß. Reinou 'Ăḥazayāh sobre Yahûdāh.

${ }^{v}{ }^{30} \mathrm{E}$ foi Yéhu' para Yizrə 'e'l. E 'Îzebel ouviu, ${ }^{30}$ e pôs-se com o cosmético preto [bappûk] (nos) olhos dela, e tornou bela a cabeça dela, e olhou para baixo através da janela.

v. $31 \mathrm{E}$ Yēhû̀ entrou pelo portão. ${ }^{31} \mathrm{E}$ disse (ela): "Acaso (teve) šālôm Zimarî, o que matou [hōrēg] os senhores dele?".

v. ${ }^{32} \mathrm{E}$ ergueu as faces dele em direção à janela, e disse: "Quem comigo? Quem?". E olharam para baixo para ele dois, três oficiais [sārîsîm]. ${ }^{32}$

33 E disse: "Fazei-a tombar" [šimț̂hāa]. ${ }^{33} \mathrm{E}$ a fizeram tombar. E foi borrifado do sangue dela a parede e os cavalos, e a atropelou.

${ }^{v}{ }^{34}$ E entrou, e comeu e bebeu, e disse: "Verificai agora a maldita ['ethäărûrāh], a esta, e sepultai a ela, porque filha de rei ela".

v. ${ }^{35} \mathrm{E}$ foram para sepultar a ela, mas não encontraram nela senão o crânio e os pés e as palmas das mãos.

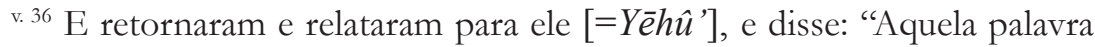
de Yhwh, que disse pela mão dele ['ăšer diber bayad-'abudô], 'Eliyyyāhû, o tišabî, dizendo: 'Na porção de terra de Yizra 'e’l, comerão os cães a carne de 'Îebel'.

${ }^{v}{ }^{37} \mathrm{E}$ será ${ }^{34}$ (o) cadáver de 'Ízebel como esterco sobre as faces do campo na porção de terra de Yizra 'e'l; que não dirão: 'Esta (é) 'T́zebel'".

\section{De praeparatione ad mortem: a presença icônica de 'Îzebel}

Com essa antiga camada literária, mesmo se preservado no texto as glosas, Robert L. Cohn (2010, p. 103) sublinha a caracterização no livro dos

\footnotetext{
30 O verbo usual para "vestir" é 'aśố; aqui é expresso sám.

31 Enquanto o texto massorético grafa bšr $r$, "através do portão", a Septuaginta ler błyr, "na cidade".

32 Ler com Qerê, šmtuhä, "jogue-a para baixo”, ao invés de Ketiv, šimtəhû, "jogue-o para baixo". Em relação aos "líderes", grafou-se "dois ou três sārîs", do acádio ša rềsi. Cogan e Tadmor (1988, p. 112) aludem ao fato de que em artefatos de palácio neoassírio se refere a "eunucos" sa rèsisi.

33 Ler $\check{s} m t w h h$ como Qerê para $\breve{m} m t w h w$ de Ketib.

34 Para a forma mais antiga do perfeito da terceira pessoa do feminino singular lamed hê no Qerê de hayat.
} 
Reis: apesar do claro desprezo do historiógrafo pelo espírito assassino de Jehu, Figura 1, ele faz Yahweh (Yhwh) louvar tais atos de violência (v. 30), ao mesmo tempo em que denuncia no militar as práticas cúlticas (além da mnèmè, no v. 31) que justificaram o extermínio. Há um gravíssimo paradoxo historiográfico!

Destarte, "um plano de fundo cúltico para o encontro entre Jezebel e Jehu não é indicado em parte alguma. Nem as referências a demônios femininos na janela são particularmente relevantes" (COGAN; TADMOR, 1988 , p. 111) para o quadro apresentado. Entretanto, são encontrados no antigo Oriente Próximo artefatos nos quais "a mulher na janela" aparece em relevo de marfim; "a imagem de uma mulher que olha para fora de uma janela é bem conhecida dos marfins da Samaria, e o retrato de Jezebel aqui recorda aquela imagem" (SWEENEY, 2013, p. 335). A estética corporal pensada como uma obra de arte,

A estética corporal pensada como uma obra de arte (fig. 2) contribui para a nossa interpretação textual, mesmo em meio ambiente inamistoso Nesse caso, a excitação sexual funciona como elemento de contrapoder ao militar, entendendo que a cabeça é ritualística - protetora do corpo e apotropaica contra a desgraça iminente. Portanto, debater a função da janela - a balaustrada - nos leva a uma tentativa de substituir o ambiente. Como sugerido por Irene J. Winter (2016, p. 185), melhor é que a tomemos como excesso para provocar a imaginação, ou para não distrair o visitante ou observador nas suas intenções. A esse propósito, o embelezamento do rosto seria suficientemente adequado.

Apondo fato material iconográfico recolhido de pesquisas arqueológicas, Amy Rebecca Gansell (2016) afirma que referências a cosméticos na Bíblia hebraica são raras como discussões sobre a fragrância, mas, quando mencionada, a maquiagem do olho tem o objetivo de emular o ideal de grandes olhos pretos. ${ }^{35}$ No versículo 30, lê-se: "E foi Yēhûu para Yizra 'e'l. E 'Ízebel ouviu, e pôs-se com o cosmético preto [bappûk] (nos) olhos dela, e tornou bela a cabeça dela, e olhou para baixo através da janela". Há uma encenação intencional. Do estojo, pûk é um antimônio em pó usado como tinta para a maquiagem facial, nas pálpebras, cílios e sobrancelhas dos olhos. No contexto das deusas, no Ciclo canônico de Ba'al (século XIII) para a purificação ritual após uma guerra e ante a chegada do Ba'al (sumério: dIŠKUR), a virgem 'Anat assim procede:

35 Para Moore (2003, p. 108-109), a narração em torno de 'Îzebel é "satírica", num contexto literário cujo gênero é uma "paródia". 


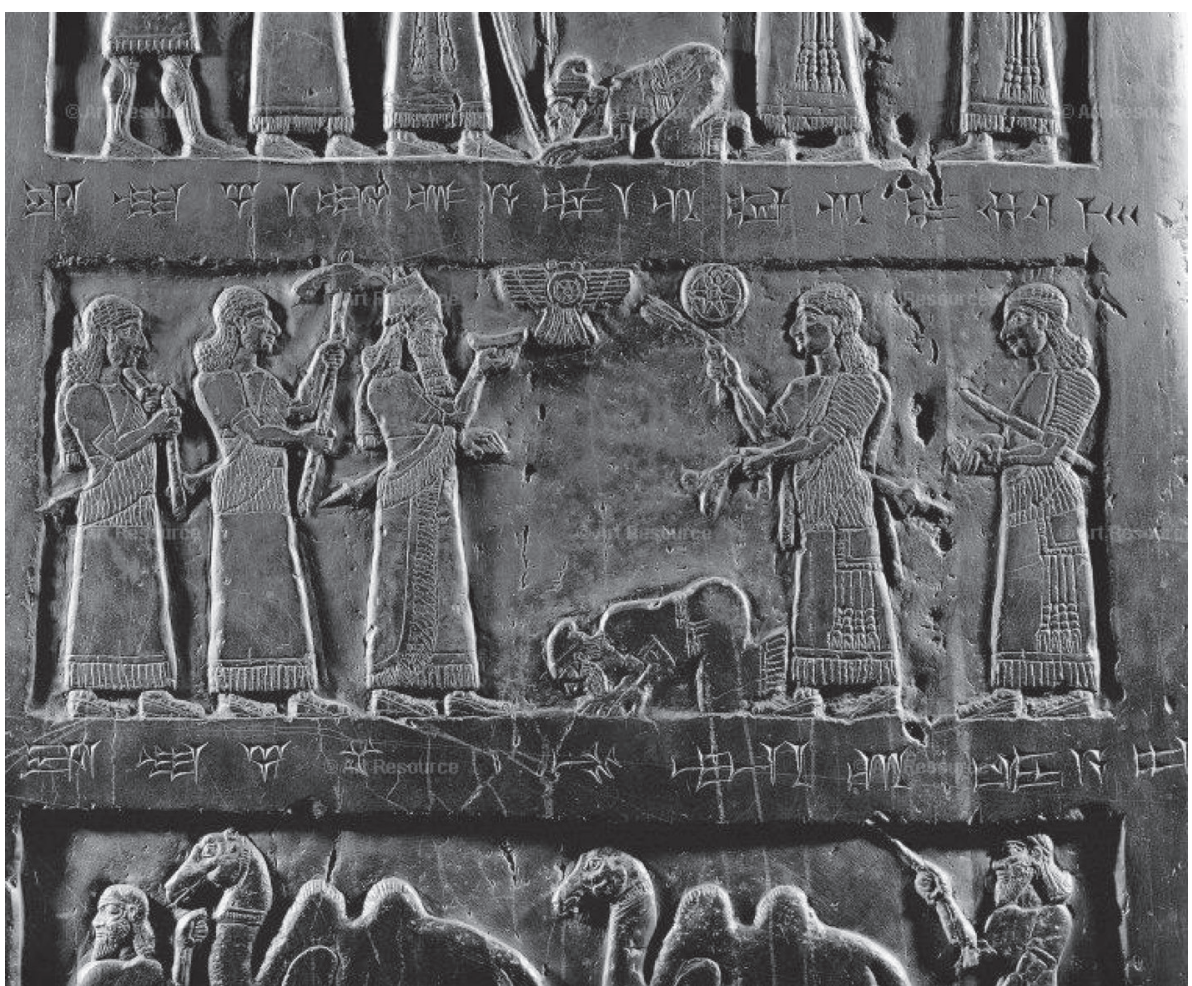

Figura 1. Detalhe do Obelisco Negro. Jehu prostrado diante do rei assírio Šulmānu-ašaridu/ Shalmaneser III. (Fonte: Art Resource ART12461).

Se maquilló (con esencia de) ostras...

Maquiou-se (com essência de) ostras... ${ }^{36}$

$*$

Apartó a las mujeres de su presencia, Apartou as mulheres de sua presença, puso una res de vacuno ante ella, pôs uma carne bovina diante dela, un cebón directamente ante su vista. um pedaço diretamente ante sua vista.

Le sacaron agua y (la) lavaron, Tiraram-lhe água e (a) lavaram, (con) rocío del cielo, aceite de la tierra, (com) orvalho dos céus, azeite da terra, (con) rocío que los cielos le vertieron (com) orvalho dos céus verteram-lhe

36 KTU 1.3 II, ritual após a guerra (OLMO LETE, 1998, p. 69; tradução do autor). 
(con) orvallo que le derramaron las estrellas.

(com) orvalho que lhe derramaram as estrelas.

Se ungió (con esencia de) ostras

Ungiu-se (com essência de) ostras

cuya exhalación (llega) a mil acres [en el mar].

cuja exalação (chega) a mil acres [no mar]. ${ }^{37}$

//

(con) orvallo del Auriga [Ba'al, dios de la tempestad y la lluvia fecundante] de las nubes

(com) orvalho do Auriga [ $\mathrm{Ba}^{\prime} \mathrm{al}$, deus da tempestade e da chuva fecundante] das nuvens

De forma assemelhada, uma referência hebraica ${ }^{38}$ utiliza um termo sinonímico raro, $k h l$ em forma verbal, "maquiar-se"; os diademas de ouro, brincos e tornozeleiras, também escavados a partir de tumbas, fornecem exemplos concretos adicionais de tipos de adorno usados por mulheres, animais e homens no Levante. Muitos desses objetos são reutilizados de tumbas, sem ignorar que objetos de luxo eram importados da Mesopotâmia e Anatólia. Estamos também aqui em ambiente sacrifical, em relação à sexualidade.

Há mais de quatro décadas René Girard (2008, p. 51) já divulgava pesquisas científicas que confirmavam que "em muitos aspectos o ponto de vista dos primitivos" indicava que "a excitação sexual e a violência anunciam-se um pouco da mesma forma. A maior parte das reações corporais mensuráveis são as mesmas em ambos os casos". Tratando-se da sexualidade, o embelezamento excitante a transforma em representação impura por relacionar-se com a violência, apesar de os ritos de embelezamento estarem em contracorrente aos ritos sacrificais. Ironicamente, é Jehu quem necessita ser "purificado", e esta é a função dos rituais de sangue e de comensalidade em torno e sobre 'Îzebel no palácio de Yizra 'e'l.

A gabîrāh ${ }^{39}$ teve tempo para lembrar de Zimrî - antigo oficial de cavalaria do exército israelita que traiu e assassinou a seu senhor, o rei 'Élāh,

${ }^{37}$ KTU 1.3 II, ritual para encontrar-se com Ba'al (OLMO LETE, 1998, p. 73; tradução do autor).

38 No livro do profeta Ezequiel 23.40 (ELLIGER; RUDOLPH, 1997).

39 Sobre a gabîrāh: "Em geral, os usos na Bíblia hebraica de gebîrâ e outros termos relacionados parecem indicar ser esse um termo de respeito que se referia a mulheres poderosas e servia como reconhecimento de sua autoridade. Como tal, não é surpreendente que se referisse a mulheres da realeza. Entretanto, o fato de referir-se a mulheres que eram rainhas-mães não quer necessariamente dizer que signifique 'rainha-mãe'. Podia ser apenas um reconhecimento da posição de poder e de autoridade que elas ocupavam. Quando se referia a uma mulher, o termo g bîrâ significava que ela era a mulher mais importante no reino na ocasião: e, nesse caso, bem podia ser a rainha-mãe, embora talvez não fosse" (SMITH, 2005, p. 151-152). 
tendo governado como usurpador por apenas sete dias - e oportunidade para mostrar o seu lado espirituoso de mãe que conhece a vida, quando numa frase nada retórica inquire Jehu: "Acaso (teve) saâlôm Zimrî, o que matou os senhores dele?" Não sendo retórica a expressão da rainha, o uso de Zimrî como exemplo é outro convite à reconciliação. Com efeito, sabemos que "o exemplo é um momento da argumentação e um expediente da persuasão" (HARTOG, 2013, p. 43).

Eis aí a sua melhor imagem: positiva na circunstancialidade! Tem-se a ideia de dignidade e distinção da gəbîrāh para a ocasião: os trajes e aparência, o espírito de autoconfiança e a demonstração de coragem. A expressão šălôm aparece onze vezes em 2Reis 9-10, nenhuma como expressão positiva na boca de Jehu e seus aliados. Mesmo em relação às camadas literárias sobre rememoração do assassinato de 'ízebel, o redator não conteve os detalhes. A inscrição ocorre anteriormente de forma abreviada.

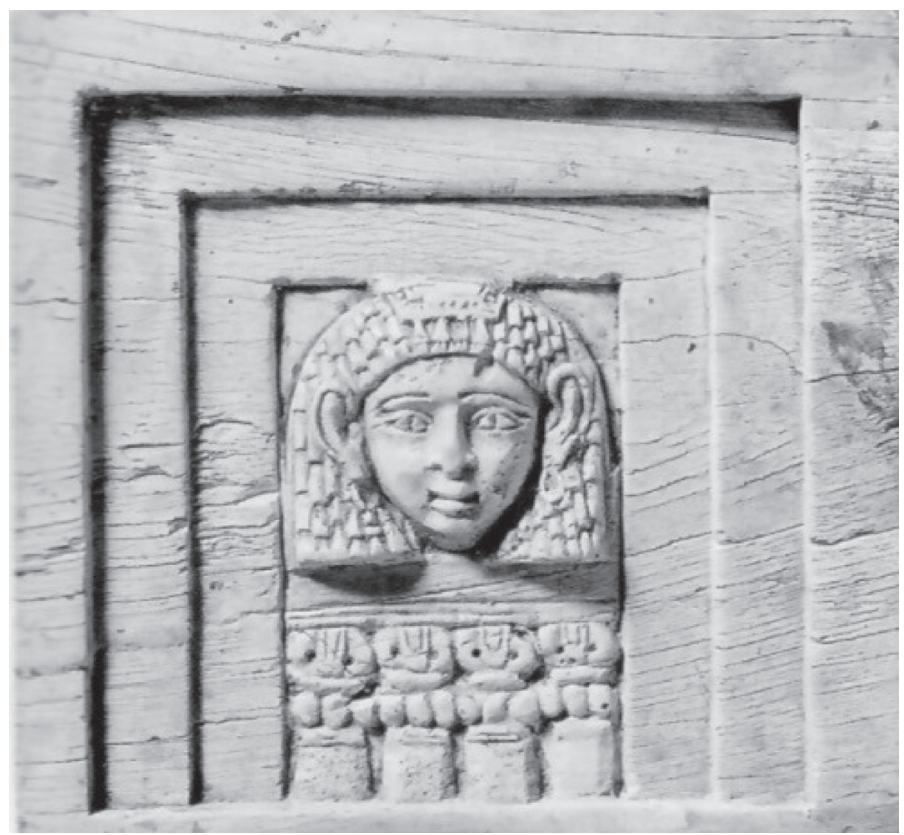

Figura 2. "A mulher na janela.". Placa de marfim e ouro datada em c. séculos IX--VIII aA.E.C.A.E.C., encontrada em Arslan Taş, Halab/ Aleppo. ( Fonte: Musée du Louvre AO 11459; cf. WINTER, 2016).

Além disso, o historiógrafo desloca o fim de 'Îzebel do anteriormente prometido "muro" ( $h l)$ para a própria planície de Yizra 'e’l, contradizendo a 
profecia. Essa discrepância favorece outra leitura, "muro ( $h l)$ de Yizra 'e'l" (1Reis 21.23), como um reflexo mais claro para o registro em 2Reis 9: 'Îzebel foi jogada da janela do palácio e morreu no muro da fortificação. Dessa forma, a leitura de 2Reis 9.36, "porção, terreno" ( $h l q)$ seria o resultado de uma escrita sem revisão, tendo aparecido duas vezes antes no mesmo capítulo, nos versículos 21 e 25. "Apenas em dois pontos o leitor discerne que a narrativa foi expandida: 9.7-10a é ancorado na fraseologia estereotipada das profecias de desgraça anteriores" (COGAN; TADMOR, 1988, p. 118). Por fim, o assassinato de Nābôt, na referência da anunciação do profeta Elias ('Eliyyāhû), e as interações culturais com populações vizinhas são as bases para o extermínio e o golpe de Estado.

Passamos agora para o ambiente de vivências coloniais do período Persa Aquemênida retroprojetado. Tanto a história de Nābôt quanto as menções a 'Îzebel são relativas ao período posterior ao exílio em Babilônia $(B \bar{a} b-i l \bar{\imath})$, período no qual se afirmara que o casamento com mulheres estrangeiras ameaçava a etnicidade e o monoteísmo em construção na colônia persa de Yəhûd. ${ }^{40} \mathrm{O}$ problema da presença identitária da rainha reside na endogamia. Ela é uma mulher não israelita com demonstradas influências no jogo político que extrapolam o palácio:

Os fenícios (especialmente a cidade Sidon que começou a superar Tiro durante o século V A.E.C.) se recuperaram sob o domínio persa e tentaram aproveitar a situação problemática no Israel pós-exílico. O rei persa deu Jaffa e Dor a Eshmunazar de Sidon (475-461 A.E.C.). Tudo isso provavelmente foi adicionado à imagem expandida de Jezabel nos tempos pós-exílicos (PRUIN, 2007, p. 227; tradução do autor). ${ }^{41}$

Vemo-la orientar o envio de carta às lideranças locais como quem tem controle dos posicionamentos políticos nacionais; com efeito:

40 Basta verificar o plano de fundo histórico dos livros de Esdras, Rute, Jonas e 1-2Macabeus (Para uma explanação, cf. SCHNIEDEWIND, 1993, p. 653-656). Dagmar Pruin (2007, p. 210-212) aborda as narrações em torno desses personagens datando-as, particularmente o núcleo das histórias, nos séculos IX-VII.

41 "The Phoenicians (especially the city Sidon that started to surpass Tyre during the fifth century BCE) recovered under Persian rule and attempted to take advantage of the problematic situation in post-exilic Israel. The Persian king gave Jaffa and Dor to Eshmunazar of Sidon (475-461 BCE). All this probably added to the expanded picture of Jezebel in post-exilic times" (PRUIN, 2007, p. 227). 
...o poder de Jezabel é reconhecido pelos súditos de Ahab. Ela escreve em nome Ahab para proclamar um jejum (1Rs 21,9-10), mas "os homens da cidade de Nabot, os anciãos e os notáveis que moravam na mesma cidade, fizeram conforme Jezabel lhes havia ordenado, segundo estava escrito nas cartas que ela lhes enviara" (1Rs 21.11) (SMITH, 2005, p. 163).

Sem dúvida, o reinado era exercido pelas mulheres. O historiógrafo sabe disso, mas nem usa a palavra mälkēh para Atalia ( ‘̆talyyāh $\hat{u})$ nem para 'İzebel, aquelas que reinam ${ }^{42}$ - um aspecto metodologicamente formalista na escrituração da história:

A representação de Jezebel é ainda pior. Mesmo o nome dela mudou, de modo que o epíteto zebul, "exaltado", se transforma em zebel, "esterco". É provável que este não seja o único aspecto de sua vida que se transformou. Já vimos a presença dela no historicamente problemático 1Reis 18. Ela também desempenha um papel significativo em 1Reis 21, onde ela convence Ahab a expropriar a vinha de Nabot. Todo o capítulo está estruturado de forma a culpá-la, e a absolver Ahab (ver, especialmente, v. 27-29). Ahab é finalmente perdoado; de fato, como o texto afirma explicitamente (v. 25), o único motivo pelo qual ele era tão perverso é que sua esposa o convenceu ao crime ("por instigação de sua esposa Jezebel”). Ela é retratada como a definição de mulher estrangeira dos Provérbios, que persuade homens, levando-os finalmente à morte (veja, por exemplo, Provérbios 7.21-23). Por suas atividades descaradas, caracterizadas como "prostituição" e "feitiçaria" (2Reis 9.22), ela finalmente não é nem mesmo enterrada inteira (2Reis 9.33-37), uma terrível desgraça da perspectiva bíblica (BRETTLER, 2007, p. 330-331; tradução do autor). ${ }^{43}$

42 Sobre a "realeza feminina", sugerimos, entre outros aqui mencionados, o estudo de Carol Smith (2005).

43 "The depiction of Jezebel is even worse. Even her name is changed, so that the epithet zebul, 'exalted', becomes transformed to zebel, 'dung' (Yee 1992, 848). It is likely that this is not the only aspect of her life that was transformed. We have already seen her presence in the historically problematic 1 Kings 18 . She also plays a significant role in 1 Kings 21, where she convinces Ahab to expropriate the vineyard of Naboth. The whole chapter is structured in such a manner as to blame her, and to absolve Ahab (see esp. v. 27-29). Ahab is ultimately forgiven; in fact, as the text states explicitly (v. 25), the only reason he was so wicked is that his wife sweet-talked him into the crime ('at the instigation of his wife Jezebel'). She is depicted as the ultimate foreign woman of Proverbs, who smoothtalks men, ultimately leading them to Death (see e.g. Prov. 7.21-23). For her brazen activities, mischaracterized as 'whoring' and 'witchcraft' (2 Kgs 9.22), she ultimately is not even be buried whole (2 Kgs 9.33-37), a terrible disgrace from the biblical perspective" (BRETTLER, 2007, p. 330-331). 
No aspecto linguístico, a conotação negativa massorética é deliberada, pois $\mathrm{Ba}$ áal também é chamado de żbl. Além de trocar a vogal, aproveitase da simplificação da fala aramaica de supressão do prenome $b a \%$, o elemento teofórico de Ba'lîzęel, "Ba'al a tem carregado", que se aproxima da vocalização de Ugarit (Ú-ga-ri-it), za-būl, "príncipe", e do amurrita zabu-lum/zu-ba-la-an. Essas resoluções literárias convergem para destacar a função daquela princesa na corte, ela é uma gabîrāh - assim se acomoda uma ocorrência cultural ligada à mulher do rei nas cortes de Hatti, Ǎ̌šū e na cidade-Estado de Ugarit. ${ }^{44}$

'Îzebel era filha de Itto-Ba'al (“Com ele está Ba 'al'; c. 891-859) $)^{45}$ de Tiro (Şurr), "rei dos sidônios". Ela é fenícia, como a maioria das peças de marfim. Além disso, é rainha-mãe num pequeno reino levantino/cannanita - dimensão político-territorial em relação aos grandes reinos, imperiais -, região onde encontramos esculturas de marfim identificadas como a "deusa da torre". A torre seria então uma metáfora para a janela alta o suficiente para provocar a morte de quem por ela seja lançado.

Seria razoável então afirmar que os usos das linguagens imagéticas na elaboração escritural basearam-se em imagens de deusas. No caso de 'ízebel, diferente

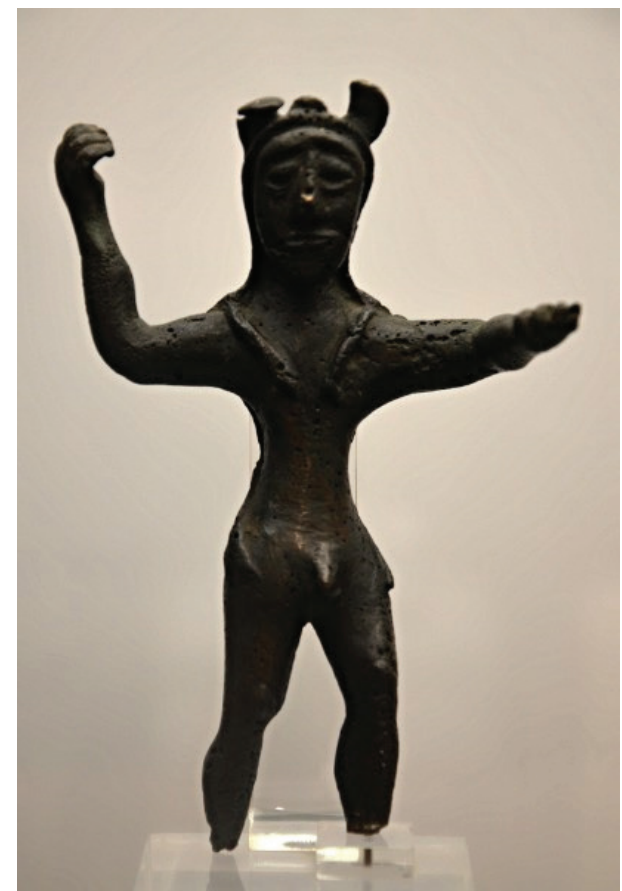

Figura 3. Deus Melqart (Fonte: Ancient.eu). de outras mulheres das elites governantes do antigo Oriente-Próximo, que sugerem atributos da fertilidade, a ambientação da guerra compõe o seu plano de fundo. Esclareça-se que a "linguagem de promiscuidade é frequentemente usada na Bíblia para

\footnotetext{
44 Diferente de Dagmar Pruin (2007, p. 224), consideramos que a autoridade da gəbîrāh não se limitava às ações familiais, tomando 'Îzebel como exemplar.

45 Anais de Şür foram preservados em língua grega nas quais constam os "feitos de Ithobaal, rei de Tiro" (SETERS, 2008, p. 210-214).
} 
associação com outros deuses"; da mesma forma, a menção a "feitiço" deve ser tomada como metáfora para "maldade" (SEOW, 1999, p. 219). No primeiro milênio A.E.C. essa tentativa de particularização começa a tomar forma apenas a partir da época Persa Aquemênida, comportamento que reflete nas camadas redacionais hebraicas coetâneas.

Antes, porém, predominam as evocações de um pequeno número de divindades maiorais de panteões ('Ilū em Kna'n/Canaan, Haddu-Ba'lu e a deusa solar Šapšu em Ugarit, Kotharu-wa-Khasisu na cidade neolítica de Kreta, Rašap na Anatólia, Dagan e 'Aštart em Mari, Ba'alšamem em Biblos, Ešmun em Sidon e na antiga ilha assíria de Alašiya/Chipre), numa ampla região - o norte do Levante, de onde procede 'Îzebel - que conta com mais de duas centenas de divindades. As cidades fenícias privilegiam um particularismo religioso para preservar seu patrimônio de cultura religiosa, caracterizado por divindades tutelares. Assim, em Tiro 'Aštart está associada a Ba'alšamem, com quem tem um filho, Melqart. Para Pierre Bordreuil e JeanJacques Glassner (2014, p. 433), “o carácter políade das divindades fenícias está explícito no nome de Melqart, que significa 'rei da cidade"'. Nesse contexto de interações culturais, "a figura de Yahweh insere-se perfeitamente no quadro das divindades oeste-semíticas".

Com efeito, há uma inversão tanto do aspecto positivo do šālôm quanto da sacralidade da figura feminina. Até mesmo "o nome da rainha 'izébel não é mais que um sobrenome irônico ('sem glória') do que um patrônimo real" (Abadie, 2009, p. 176). ${ }^{46}$ Ignorou-se à época das compilações das memórias e tradições que a ideia de religião do casal real 'Îzebel e 'Aḥ'āb, difundida com reminiscências das divindades do Levante e particularmente das culturas de Canaan, prevaleceu por transmitir aos israelitas uma identificação de autoctonia, como um povo realmente da terra ('am hā'āreș).

Em adição, após analisar os contextos históricos das iconografias, Winter (2016, p. 186) postula a possibilidade de que "a história de Jezebel representa uma inversão do que originalmente era um significado auspicioso em uma paródia possivelmente erótica e transgressora”. Acrescentemos que a rainha seria então uma personagem puramente literária da narração romanesca entre uma esposa fenícia e um marido israelita, com memória de poder de natureza mais literária do que naturalmente histórica. Retrospectivamente, como figura histórica ela é antes de tudo uma elaboração literária.

46 Outra translação possível para 'T́zebel seria "Príncipe" (= Ba'al), "Princesa". 

israelita do século IX A.E.C. nos contextos das linguagens culturais levantinas

\section{Referências}

ABADIE, Ph. L'histoire d'Israël entre mémoire et relecture. Paris: Éditions du Cerf, 2009.

BORDREUIL, P.; GLASSNER, J.-J. L'organisation des pantheons. In: BORDREUIL, P.; BRIQUEL-CHATONNET, Fr.; MICHEL, C. (Dir.). Les débuts de l'Histoire: civilisations et cultures du Proche-Orient ancien. Nouvelle édition revue et augmentée. Paris: Éditions Khéops, 2014, p. 428-434.

BRETTLER, M. Z. Method in the application of biblical source material to historical writing (with particular reference to the ninth century BCE). In: WILLIAMSON, H. G. M. (Org.). Understanding the history of ancient Israel. Proceedings of the British Academy 143. Oxford: Oxford University Press, 2007, p. 305-336.

COGAN, M.; TADMOR, H. II Kings. Anchor Bible 11. Garden City, NY: Doubleday, 1988.

COHN, R. L. Characterization in Kings. In: LEMAIRE, A.; HALPERN, B. (Orgs.). The Books of Kings: sources, composition, historiography, and reception. Atlanta, GA: SBL Press, 2010, p. 89-105.

ELLIGER, K.; RUDOLPH, W. (Hrsg.). Biblia Hebraica Stuttgartensia. 5. aufl. Stuttgart: Deutsche Bibelgesellschaft, 1997.

GANSELL, A. R. The iconography of ideal feminine beauty represented in the Hebrew Bible and Iron Age levantine ivory sculpture. In: HULSTER, I. J. de; LEMON, J. M. (Orgs.). Image, text, exegesis: iconographic interpretation and the Hebrew Bible. London: Bloomsbury, 2016, p. 46-70.

GIRARD, R. A violência e o sagrado. 3. ed. Trad. de M. C. Gambini. São Paulo, SP: Paz e Terra, 2008.

GZELLA, H. Peoples and languages of the Levant during the Bronze and Iron Ages. In: STEINER, M. L.; KILLEBREW, A. E. (Orgs.). The Oxford handbook of the archaeology of the Levant: c. 8000-332 BCE. Oxford: Oxford University Press, 2014, p. 24-34.

HARTOG, Fr. Evidência da história: o que os historiadores veem. Trad. de G. J. de F. Teixeira. Belo Horizonte, MG: Autêntica, 2013.

MEILLET, A. Como as palavras mudam de sentido. Org. e edição de R. F. Benthien e M. S. Palmenta. São Paulo: Edusp, 2016.

MOORE, M. S. Jehu's coronation and purge of Israel. Vetus Testamentum, Leiden, v. LIII, n. 1, p. 97-114, 2003.

OLMO LETE, G. del (Edición y traducción). Mitos, leyendas y rituals de los semitas occidentales. Madrid; Barcelona: Trotta; Edicions de la Universitat de Barcelona, 1998.

PRUIN, D. What is in a text? - Searching for Jezebel. In: WILLIAMSON, H. G. M. (Org.). Understanding the history of ancient Israel. Proceedings of the British Academy 143. Oxford: Oxford University Press, 2007, p. 208-235.

RAHLFS, A.; HANHART, R. (Hrsg.). Septuaginta: Id est Vetus Testamentum graece iuxta LXX interpretes. Editio altera. Vols. 1 e 2. Stuttgart: Deutsche Bibelgesellschaft, 2006. 
SANTOS, J. B. R. Contra o etnocídio do profeta 'Éliyyābû, o tišěbî: Conflito e apropriação de lugar sagrado em um pequeno reino do Levante. Estudo de fonte hebraica. In:

Primeiro Testamento: estudos teóricos e exegéticos. São Bernardo do Campo: Editeo, 2018, p. 151-167. [http://dx.doi.org/10.15448/2178-3748.2017.2.23675]

SCHNIEDEWIND, W. M. History and interpretation: the religion of Ahab and Manasseh in the Book of Kings. Catholic Biblical Quarterly, Washington, D.C., v. 55, n. 4, p. 649661, 1993.

SEOW, C.-L. The First and Second Books of Kings: introduction, commentary, and reflections. In: ALEXANDER, N. M. (Org.). The New Interpreter's Bible, v. III. Nashville, TN: Abingdon Press, 1999, p. 1-295.

SETERS, J. van. Em busca da história: historiografia no mundo antigo e as origens da história bíblica. Trad. de S. M. de L. Mello. São Paulo: Edusp, 2008.

SMITH, C. "Realeza feminina" em Israel? Os casos de Betsabéia, Jezabel e Atalia. In: DAY, J. (Org.). Rei e messias em Israel e no antigo Oriente Próximo. Dissertações do Seminário Veterotestamentário de Oxford. Trad. de Barbara Theoto Lambert. São Paulo: Paulinas, 2005, p. $149-169$.

SOUTHWOOD, K. The social and cultural history of ancient Israel. In: BARTON, J. (Org.). The Hebrew Bible: a critical companion. Princeton, NJ: Princeton University Press, 2016, p. 54-85.

SWEENEY, M. A. I \& II Kings: a commentary. Louisville, KE: Westminster John Knox Press, 2013.

WALTKE, B. K.; O'CONNOR, M. P. Introdução à sintaxe do hebraico bíblico. Trad. de F. A. Ferreira et al. São Paulo: Editora Cultura Cristã, 2006.

WINTER, I. J. The "Woman at the window": iconography and inferences of a motif in FirstMillennium B.C. In: ARUZ, J.; SEYMOUR, M. (Orgs.). Assyria to Iberia: art and culture in the Iron Age. New York; New Haven: The Metropolitan Museum of Art; Yale University Press, 2016, p. 180-193.

Submetido em: 10-7-2019

Aceito em: 4-12-2019 